\title{
Pemodelan Persentase Penduduk Miskin Kabupaten/Kota di Provinsi Jawa Barat dengan Pendekatan Regresi Nonparametrik Spline Truncated
}

\author{
Andrea Tri Rian Dani ${ }^{(1)}$, Ludia Ni'matuzzahroh ${ }^{(2)}$ \\ Institut Teknologi Sepuluh Nopember \\ Jl. Arif Rahman Hakim, Kota Surabaya 60111, Jawa Timur, Indonesia \\ e-mail: andreatririandani98@gmail.com, ludianimatuzzahroh@gmail.com
}

\begin{abstract}
ABSTRAK
Estimator Spline Truncated adalah bentuk dari polinomial yang tersegmen dan bersifat kontinu, serta memiliki fleksibilitas yang tinggi dalam proses pemodelan. Estimator ini termasuk kedalam pendekatan regresi nonparametrik yang dapat digunakan ketika bentuk hubungan antara variabel respon dan variabel prediktor menunjukkan pola yang berubah-ubah pada sub-sub interval tertentu. Penelitian ini bertujuan untuk memodelkan persentase penduduk miskin Kabupaten/Kota di Provinsi Jawa Barat dengan menggunakan model regresi nonparametrik estimator Spline Truncated. Metode estimasi yang digunakan adalah Ordinary Least Squares (OLS). Kriteria kebaikan model yang digunakan adalah Generalized CrossValidation (GCV). Berdasarkan hasil analisis, didapatkan model terbaik regresi nonparametrik Spline Truncated, yaitu model dengan 3 titik knot, dimana diperoleh nilai GCV minimum sebesar 2.14. Berdasarkan hasil pengujian hipotesis, baik secara simultan maupun parsial, diketahui bahwa variabel prediktor yang digunakan pada penelitian ini, berpengaruh signifikan terhadap persentase penduduk miskin, dengan nilai koefisien determinasi sebesar $95.33 \%$.
\end{abstract}

Kata kunci : Generalized Cross-Validation (GCV), Persentase Penduduk Miskin, Spline Truncated.

ABSTRACT

The Truncated Spline Estimators are polynomial pieces that have segmented and continuous properties and have high flexibility in the modeling process. The truncated Spline is one approach in nonparametric regression that can be used when the pattern of the relationship between the response variable and the predictor variable varies in certain sub-intervals. The purpose of this study is to model the percentage of poor people in districts/cities in West Java Province using a nonparametric regression model of the Spline Truncated estimator. The estimation method used is Ordinary Least Squares (OLS). The criteria for the goodness of the nonparametric regression model used is the Generalized Cross-Validation $(G C V)$. Based on the analysis, the best model is obtained from the Truncated Spline nonparametric regression, namely the model with 3-knot points, where the minimum GCV value is 2.14. Based on the results of hypothesis testing, both simultaneously and partially, it is known that the predictor variables used in this study have a significant effect on the percentage of poor people, with a coefficient of determination of $95.33 \%$.

Keywords : Generalized Cross-Validation (GCV), Percentage of Poor People, Truncated Spline.

\section{PENDAHULUAN}

Analisis regresi merupakan salah satu metode statistik yang dapat digunakan untuk mengetahui bentuk pola hubungan antara variabel respon dan variabel prediktor (Draper \& Smith, 1992), (Montgomery, dkk., 2012). Tujuan utama pemodelan menggunakan analisis regresi adalah menentukan bentuk dari estimasi kurva regresi yang tepat (Budiantara, 2019). Bentuk hubungan dari variabel respon (dependen) dengan variabel prediktor (independen) dapat didekati dengan pendekatan regresi nonparametrik.

Regresi nonparametrik dapat digunakan pada saat bentuk kurva regresi memiliki pola yang tidak diketahui. Salah satu estimator yang paling banyak digunakan dalam pemodelan dengan pendekatan regresi nonparametrik adalah estimator Spline Truncated. Hal ini dikarenakan pendekatan dengan model regresi nonparametrik yaitu Spline Truncated mempunyai interpretasi statistik dan

Andrea Tri Rian Dani ${ }^{1}$, Ludia Ni'matuzzahroh ${ }^{2} /$

J Statistika Vol. 14, No. 1, (2021) 
visual yang spesial dalam prakteknya dan sangat baik (Eubank, 1999). Selain itu, estimator Spline Truncated memiliki keunggulan karena mampu menangani perubahan data yang berubah-ubah pada interval-interval tertentu (Budiantara, 2009); (Dani \& Adrianingsih, 2021). Dalam membangun model regresi menggunakan estimator Spline Truncated, ada beberapa hal yang perlu diperhatikan, diantaranya menentukan derajat dari model regresi, jumlah titik knot, dan lokasi titik knot berada (Montoya, dkk., 2014). Dengan menggunakan titik knot, kurva regresi dengan Spline Truncated mampu menangani problematika perubahan pola data yang tajam, sehingga memungkinkan untuk diperoleh hasil estimasi kurva yang relatif mulus (Dani, dkk., 2021).

Kelebihan dari estimator Spline Truncated itu sendiri yaitu memberikan perhitungan matematis yang lebih mudah dan sederhana. Adapun beberapa penelitian sebelumnya yang menggunakan pendekatan regresi nonparametrik dengan estimator Spline Truncated, diantaranya Yanthi dan Budiantara (2016); Saputro, dkk. (2018); Rahim, dkk. (2019); Sholikha, dkk. (2019); dan Dani, dkk. (2021).

Dalam analisis statistika, selain melakukan analisis statistika deskriptif juga perlu dilakukan analisis statistika inferensia, seperti pengujian hipotesis, baik secara secara simultan dan parsial terhadap parameter model untuk mengetahui apakah parameter tersebut signifikan terhadap model atau tidak. Beberapa penelitian mengenai pengujian hipotesis dalam regresi nonparametrik dengan estimator Spline Truncated, diantaranya Bidari dan Budiantara (2020) dan Dani, dkk. (2020).

Model regresi nonparametrik dapat diterapkan dalam berbagai disiplin ilmu seperti sosial, ekonomi, dan kedokteran. Salah satu kajian pada bidang sosial yang dapat diterapkan dalam pemodelan regresi nonparametrik dengan estimator Spline Truncated adalah masalah kemiskinan. Kemiskinan merupakan salah satu masalah yang serius yang dihadapi Indonesia, khususnya pada Provinsi Jawa Barat. Berdasarkan data BPS pada Bulan Maret 2020, di Provinsi Jawa Barat besarnya persentase penduduk miskin yaitu $7.88 \%$, kemudian pada Bulan September 2020 menjadi sebesar $8.43 \%$, sehingga dalam waktu satu tahun mengalami peningkatan sebesar $0.55 \%$.

Berdasarkan paparan di atas, maka pada penelitian ini akan digunakan pendekatan regresi nonparametrik dengan estimator Spline Truncated dalam memodelkan persentase penduduk miskin
Kabupaten/Kota di Provinsi Jawa Barat pada Tahun 2020, kemudian akan dilakukan analisis statistika inferensia yaitu pengujian hipotesis baik secara simultan maupun parsial terhadap parameter model regresi yang dihasilkan. Manfaat yang diharapkan dari hasil penelitian ini yaitu adalah menambah wawasan keilmuan mengenai regresi nonparametrik Spline Truncated dan dapat dijadikan masukan untuk pemerintah daerah dan pemerintah pusat dalam menentukan kebijakan pemberantasan kemiskinan.

\section{METODE PENELITIAN}

Bagian metodologi penelitian ini menjelaskan tentang sumber data, variabel penelitian, serta langkah-langkah analisis data yang akan digunakan untuk mengatasi masalah Persentase Penduduk Miskin Kabupaten/Kota di Provinsi Jawa Barat Tahun 2020.

\subsection{Data Penelitian}

Penelitian ini menggunakan data sekunder yang dipublikasikan oleh Badan Pusat Statistik (BPS). Unit observasi yang digunakan adalah Kabupaten/Kota di Provinsi Jawa Barat Tahun 2020 sebanyak 25 Kabupaten/Kota.

Variabel yang digunakan terdiri dari satu variabel respon (Y) dan empat variabel prediktor (X). Variabel-variabel penelitian telah disajikan pada Tabel 1 sebagai berikut:

Tabel 1. Variabel Penelitian

\begin{tabular}{ccc}
\hline Variabel & $\begin{array}{c}\text { Simbol } \\
\text { Variabel }\end{array}$ & Deskripsi \\
\hline Respon & $Y$ & Persentase Penduduk Miskin \\
\hline & $X_{1}$ & Angka Harapan Hidup \\
\cline { 2 - 3 } Prediktor & $X_{2}$ & Rata-Rata Lama Sekolah \\
\cline { 2 - 3 } & $X_{3}$ & Gini Ratio \\
\cline { 2 - 3 } & $X_{4}$ & Tingkat Pengangguran \\
& & Terbuka \\
\hline
\end{tabular}

\subsection{Tahapan Analisis Data}

Berikut ini merupakan tahapan-tahapan analisis dalam pemodelan regresi nonparametrik dengan estimator Spline Truncated:

1. Melakukan identifikasi setiap variabel penelitian menggunakan statistika deskriptif.

2. Membentuk scatter plot antara variabel respon dengan setiap variabel prediktor.

3. Melakukan deteksi multikolinearitas pada setiap variabel prediktor.

4. Memodelkan data Persentase Penduduk Miskin Kabupaten/Kota di Provinsi Jawa Barat Tahun 2020 dengan model regresi nonparametrik Spline Truncated. 
5. Memilih titik knot optimal yang menghasilkan nilai Generalized Cross-Validation (GCV) minimum.

6. Menghitung nilai koefisien determinasi $\left(\mathrm{R}^{2}\right)$.

7. Melakukan pengujian hipotesis secara simultan (Uji F).

8. Melakukan pengujian hipotesis secara parsial (Uji t).

9. Pengujian asumsi klasik yaitu, asumsi residual identik, asumsi residual independen, dan asumsi residual berdistribusi normal.

\section{HASIL DAN PEMBAHASAN}

Pada bagian hasil dan pembahasan ini akan dijelaskan mengenai pemodelan persentase penduduk miskin Kabupaten/Kota di Provinsi Jawa Barat dengan Regresi Nonparametrik Spline Truncated.

\subsection{Statistika Deskriptif}

Berikut akan ditampikan statistika deskriptif yang dapat memberikan informasi awal tentang masingmasing variabel yang digunakan, baik variabel respon maupun variabel prediktor pada Tabel 2 .

Tabel 2. Statistika Deskriptif

\begin{tabular}{ccccc}
\hline Variabel & Minimum & Maksimum & $\begin{array}{c}\text { Rata- } \\
\text { Rata }\end{array}$ & $\begin{array}{c}\text { Standar } \\
\text { Deviasi }\end{array}$ \\
\hline$Y$ & 2.45 & 12.97 & 8.42 & 2.80 \\
\hline$X_{1}$ & 69.47 & 75.01 & 72.24 & 1.40 \\
\hline$X_{2}$ & 11.7 & 14.2 & 12.79 & 0.77 \\
\hline$X_{3}$ & 0.31 & 0.42 & 0.36 & 0.03 \\
\hline$X_{4}$ & 5.08 & 14.29 & 9.98 & 2.38 \\
\hline
\end{tabular}

\subsection{Diagram Pencar}

Bentuk pola hubungan antar variabel respon dengan setiap variabel prediktor, dapat dilihat dengan menggunakan bantuan diagram pencar (scatter plot) yang ditampilkan pada Gambar 1.

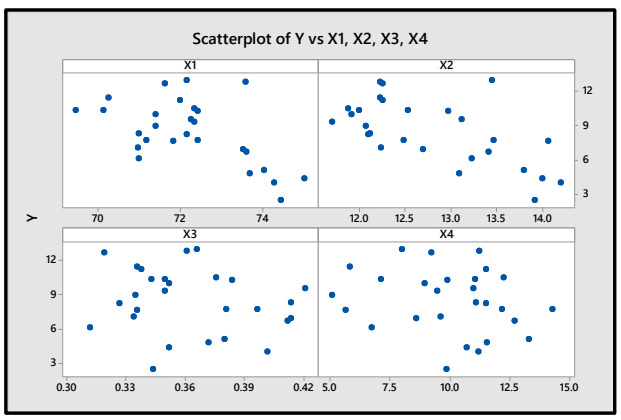

Gambar 1. Diagram Pencar

Berdasarkan Gambar 1, dapat diketahui bahwa pola hubungan antara variabel respon dengan setiap variabel prediktor terlihat tidak mengikuti bentuk pola tertentu, yang selanjutnya diduga memiliki pola yang berubah pada sub-sub interval tertentu, sehingga akan digunakan pendekatan regresi nonparametrik dengan estimator Spline Truncated.

\subsection{Deteksi Multikolinearitas}

Pada kasus pemodelan menggunakan analisis regresi, tidak diperbolehkan apabila terdapat masalah multikolinearitas pada setiap variabel prediktor. Akan digunakan nilai Variance Inflation Factor (VIF) untuk mendeteksi masalah multikolinearitas.

Tabel 3. Nilai VIF

\begin{tabular}{cc}
\hline Variabel & $\begin{array}{c}\text { Variance Inflation } \\
\text { Factor (VIF) }\end{array}$ \\
\hline$X_{1}$ & 2.01 \\
\hline$X_{2}$ & 1.72 \\
\hline$X_{3}$ & 1.46 \\
\hline$X_{4}$ & 1.62 \\
\hline
\end{tabular}

Berdasarkan Tabel 3, dapat diketahui jika tidak terdapat nilai VIF yang lebih dari 10 , sedemikian sehingga tidak terdapat masalah multikolinearitas pada variabel prediktor yang digunakan pada kasus ini.

\subsection{Pemodelan Regresi Nonparametrik dengan Estimator Spline Truncated}

1. Pemilihan Titik Knot Optimal

Pada bagian ini, akan dibahas mengenai proses pemilihan titik yang optimal. Langkah awal yang dilakukan adalah menentukan banyaknya titik knot serta lokasi dimana titik knot berada. Penelitian ini menggunakan jumlah titik knot dengan jumlah yang sama untuk setiap variabel prediktor, yaitu 1 sampai dengan 3 titik knot. Model regresi nonparametrik yang terbaik, akan dipilih dengan melihat nilai GCV terkecil dari beberapa model yang dicobakan.

Tabel 4. Nilai GCV

\begin{tabular}{cccccc}
\hline Banyaknya & \multicolumn{5}{c}{ Lokasi Titik Knot } \\
\cline { 2 - 5 } Knot & $\boldsymbol{X}_{\mathbf{1}}$ & $\boldsymbol{X}_{\mathbf{2}}$ & $\boldsymbol{X}_{\mathbf{3}}$ & $\boldsymbol{X}_{\mathbf{4}}$ & \\
\hline 1 & 72.01 & 12.85 & 0.36 & 9.30 & 6.29 \\
\hline \multirow{2}{*}{2} & 71.05 & 12.41 & 0.34 & 7.71 & \multirow{2}{*}{3.02} \\
& 71.58 & 12.65 & 0.35 & 8.59 & \\
\hline \multirow{2}{*}{3} & 70.16 & 12.01 & 0.33 & 6.23 & \\
& 70.62 & 12.22 & 0.34 & 6.99 & 2 \\
& 71.55 & 12.64 & 0.35 & 8.54 & \\
\hline
\end{tabular}

Berdasarkan Tabel 4, terlihat bahwa model regresi nonparametric dengan estimator Spline Truncated terbaik adalah model dengan 3 titik knot, dimana diperoleh nilai GCV terkecil yaitu sebesar 2.14.

Andrea Tri Rian Dani ${ }^{1}$, Ludia Ni'matuzzahroh ${ }^{2} /$ 
Adapun lokasi titik knot yang optimal untuk setiap variabel prediktor sebagai berikut:

Pada variabel $X_{1}$ (Angka Harapan Hidup)

$K_{1}=70.16 \quad K_{2}=70.62 \quad K_{3}=71.55$

Pada variabel $X_{2}$ (Rata-Rata Lama Sekolah)

$K_{1}=12.01 \quad K_{2}=12.22 \quad K_{3}=12.64$

Pada variabel $X_{3}$ (Gini Ratio)

$K_{1}=0.33 \quad K_{2}=0.34 \quad K_{3}=0.35$

Pada variabel $X_{4}$ (Tingkat Pengangguran Terbuka)

$K_{1}=6.23 \quad K_{2}=6.99 \quad K_{3}=8.54$

Selanjutnya akan dituliskan model regresi nonparametrik Spline Truncated terbaik:

$$
\begin{aligned}
\hat{y}= & \hat{\beta}_{0}+\hat{\beta}_{1} X_{1}+\hat{\beta}_{2}\left(X_{1}-70.16\right)_{+}+\cdots+\hat{\beta}_{4}\left(X_{1}-71.55\right)_{+}+ \\
& \hat{\beta}_{5} X_{2}+\hat{\beta}_{6}\left(X_{2}-12.01\right)_{+}+\cdots+\hat{\beta}_{8}\left(X_{2}-12.64\right)_{+}+ \\
& \hat{\beta}_{9} X_{3}+\hat{\beta}_{10}\left(X_{3}-0.33\right)_{+}+\cdots+\hat{\beta}_{12}\left(X_{3}-0.35\right)_{+}+ \\
& \hat{\beta}_{13} X_{4}+\hat{\beta}_{14}\left(X_{4}-6.23\right)_{+}+\cdots+\hat{\beta}_{16}\left(X_{4}-8.54\right)_{+}
\end{aligned}
$$

Nilai Koefisien Determinasi $\left(\mathrm{R}^{2}\right)$ yang dihasilkan, yaitu sebesar $95.33 \%$.

\section{Pengujian Hipotesis Simultan}

Berdasarkan dari hasil pemilihan titik knot yang optimal, maka langkah selanjutnya adalah melakukan estimasi dan pengujian parameter model secara simultan. Hipotesis yang digunakan pada pengujian hipotesis simultan sebagai berikut: Hipotesis

$H_{0} \quad: \beta_{1}=\beta_{2}=\cdots=\beta_{16}=0$

$H_{1} \quad:$ Minimal terdapat satu $\beta_{j} \neq 0$,

$$
j=1,2, \ldots, 16
$$

Dengan taraf signifikansi sebesar 5\% dan Daerah Kritis yaitu Tolak $H_{0}$ jika $F_{h i t}>F_{(\alpha, k, n-k-1)}$ maka:

Tabel 5. ANOVA

\begin{tabular}{ccccc}
\hline Sumber & df & SS & MS & Fhit \\
\hline Regresi & 16 & 195.43 & 12.21 & 34.44 \\
\hline Error & 10 & 9.57 & 0.35 & \\
\hline Total & 26 & 205.02 & & \\
\hline
\end{tabular}

Berdasarkan Tabel 5, diperoleh nilai $F_{\text {hit }}$ sebesar 34.44 dimana lebih besar daripada nilai $F_{(0.05,16,10)}$ sebesar 2.83, sehingga diputuskan Tolak $H_{0}$. Dapat disimpulkan jika minimal terdapat satu parameter yang signifikan terhadap variabel respon. Selanjutnya perlu dilakukan pengujian secara parsial guna mengetahui parameter-parameter yang memberikan pengaruh signifikan.

\section{Pengujian Parameter secara Parsial}

Pada tahapan ini, akan dilakukan pengujian signifikansi parameter secara parsial dengan hipotesis sebagai berikut:

Hipotesis

Andrea Tri Rian Dani ${ }^{1}$, Ludia Ni'matuzzahroh ${ }^{2} /$ J Statistika Vol. 14, No. 1, (2021)

\begin{tabular}{|c|c|c|c|c|}
\hline \multirow[t]{2}{*}{ Variabel } & \multicolumn{2}{|c|}{$\begin{array}{c}\text { Estimasi } \\
\text { Parameter }\end{array}$} & \multirow{2}{*}{$\begin{array}{c}P \text {-Value } \\
1.08 \times 10^{-2}\end{array}$} & \multirow{2}{*}{$\begin{array}{c}\text { Kesimpulan } \\
\text { Signifikan }\end{array}$} \\
\hline & $\hat{\beta}_{0}$ & -515.88 & & \\
\hline \multirow{4}{*}{$X_{1}$} & $\hat{\beta}_{1}$ & 7.41 & $1.03 \times 10^{-2}$ & Signifikan \\
\hline & $\hat{\beta}_{2}$ & -27.59 & $4.89 \times 10^{-5}$ & Signifikan \\
\hline & $\hat{\beta}_{3}$ & 31.47 & $7.06 \times 10^{-7}$ & Signifikan \\
\hline & $\hat{\beta}_{4}$ & -13.34 & $6.59 \times 10^{-8}$ & Signifikan \\
\hline \multirow{4}{*}{$X_{2}$} & $\hat{\beta}_{5}$ & 3.94 & $2.39 \times 10^{-1}$ & $\begin{array}{c}\text { Tidak } \\
\text { Signifikan }\end{array}$ \\
\hline & $\hat{\beta}_{6}$ & 17.89 & $1.17 \times 10^{-2}$ & Signifikan \\
\hline & $\hat{\beta}_{7}$ & -37.17 & $4.71 \times 10^{-6}$ & Signifikan \\
\hline & $\hat{\beta}_{8}$ & 15.30 & $1.06 \times 10^{-5}$ & Signifikan \\
\hline \multirow{4}{*}{$X_{3}$} & $\hat{\beta}_{9}$ & -143.93 & $3.62 \times 10^{-3}$ & Signifikan \\
\hline & $\hat{\beta}_{10}$ & 262.65 & $1.77 \times 10^{-4}$ & Signifikan \\
\hline & $\hat{\beta}_{11}$ & 105.55 & $2.47 \times 10^{-1}$ & $\begin{array}{c}\text { Tidak } \\
\text { Signifikan }\end{array}$ \\
\hline & $\hat{\beta}_{12}$ & -223.13 & $3.93 \times 10^{-4}$ & Signifikan \\
\hline \multirow{4}{*}{$X_{4}$} & $\hat{\beta}_{13}$ & 0.54 & $7.26 \times 10^{-1}$ & $\begin{array}{c}\text { Tidak } \\
\text { Signifikan }\end{array}$ \\
\hline & $\hat{\beta}_{14}$ & 6.59 & $1.03 \times 10^{-1}$ & $\begin{array}{c}\text { Tidak } \\
\text { Signifikan }\end{array}$ \\
\hline & $\hat{\beta}_{15}$ & -11.35 & $8.42 \times 10^{-3}$ & Signifikan \\
\hline & $\hat{\beta}_{16}$ & 3.92 & $3.23 \times 10^{-3}$ & Signifikan \\
\hline
\end{tabular}

$H_{0} \quad: \beta_{j}=0$

$H_{1} \quad: \beta_{j} \neq 0, j=1,2, \ldots, 16$

Dengan taraf signifikansi sebesar 5\%, maka:

Tabel 6. Estimasi Parameter dan Uji t

Berdasarkan Tabel 6, diketahui bahwa terdapat beberapa parameter yang tidak signifikan. Dari 16 parameter yang ada pada model, terdapat 4 parameter yang tidak signifikan, dikarenakan memiliki $P$-Value yang lebih besar dari taraf signifikansi yang telah ditentukan yaitu sebesar 5\% (0.05). Meskipun demikian, dapat disimpulkan secara garis besar bahwa semua variabel berpengaruh terhadap variabel respon yaitu persentase penduduk miskin Kabupaten/Kota di Jawa Barat.

\subsection{Uji Asumsi}

1. Asumsi Residual Identik

Pengujian asumsi residual identik dapat dilakukan untuk melihat residual dari hasil pemodelan memiliki varians yang sama (homogen) atau tidak. Adapun hipotesis yang digunakan sebagai berikut:

Hipotesis

$H_{0} \quad: \sigma_{1}^{2}=\sigma_{2}^{2}=\cdots=\sigma_{n}^{2}=\sigma^{2}$

$H_{1} \quad$ : Minimal terdapat satu $\sigma_{i}^{2} \neq \sigma^{2}$, untuk $i=1,2, \ldots, n$

Dengan menggunakan uji Glejser, didapatkan hasil sebagai berikut: 
Tabel 7. Uji Glejser

\begin{tabular}{ccccc}
\hline Sumber & Df & SS & MS & Fhit \\
\hline Regresi & 16 & 2.09 & 0.13 & 0.71 \\
\hline Error & 10 & 1.85 & 0.18 & \\
\hline Total & 26 & 3.94 & & \\
\hline
\end{tabular}

Berdasarkan Tabel 7, diperoleh nilai $F_{\text {hit }}$ sebesar 0.71 dimana lebih kecil dari nilai $F_{(0.05,16,10)}$ sebesar 2.83, sehingga diputuskan gagal Tolak $H_{0}$. Dapat disimpulkan bahwa residual dari hasil pemodelan adalah homogen atau dapat dikatakan tidak terjadi masalah heteroskedastisitas.

\section{Asumsi Residual Independen}

Pengujian asumsi residual independen digunakan untuk melihat ataupun mendeteksi apakah ada otokorelasi antar residual dari hasil pemodelan. Pada penelitian ini, digunakan grafik ACF untuk mendeteksi masalah otokorelasi. Asumsi residual independen terpenuhi apabila tidak ada lag pada grafik ACF yang keluar dari batas signifikansi yang telah ditentukan. Ditampilkan grafik ACF dari residual pada Gambar 2.

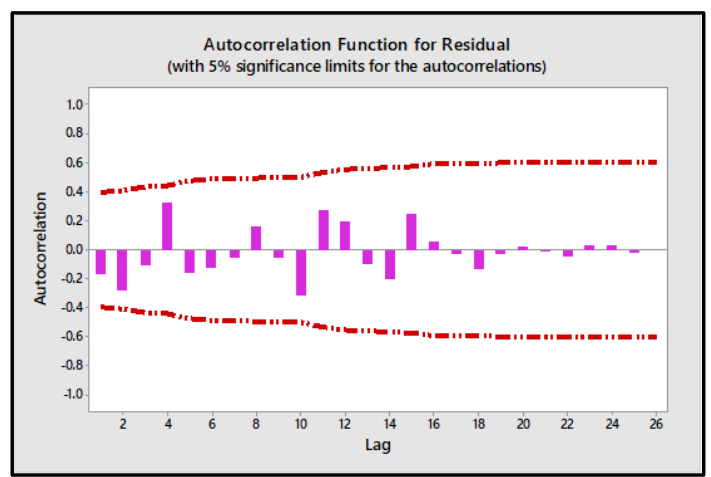

Gambar 2. Grafik ACF dari Residual

Berdasarkan Gambar 2, diketahui jika tidak ada satupun lag yang keluar dari batas signifikansi, sehingga terbukti tidak terjadi masalah otokorelasi.

\section{Asumsi Residual Berdistribusi Normal}

Statistik uji yang digunakan pada penelitian ini untuk mendeteksi residual berdistribusi normal adalah Kolmogorov-Smirnov. Adapun hipotesis yang digunakan sebagai berikut: Hipotesis

$H_{0} \quad$ : Residual berdistribusi Normal

$H_{1} \quad$ : Residual tidak berdistribusi Normal Dengan taraf signifikansi sebesar 5\%, maka:

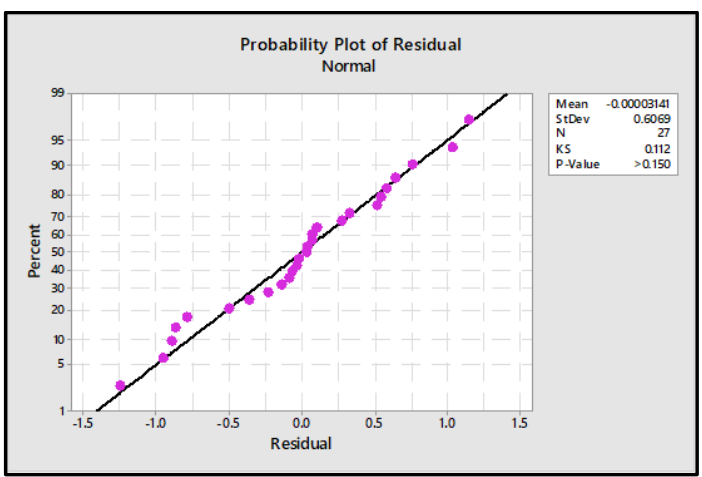

Gambar 3. Uji Normalitas Residual

Berdasarkan Gambar 3, secara visual dapat diketahui bahwa titik-titik persebaran residual memiliki kecenderungan tersebar di persekitaran garis dan cenderung mengikuti garis linear, hal ini didukung dengan nilai $P$-Value yang didapatkan lebih besar dari 0.05 , sedemikian sehingga dapat disimpulkan jika asumsi dari residual berdistribusi normal telah terpenuhi.

\subsection{Pembahasan}

Model regresi nonparametrik dengan estimator Spline Truncated dapat digunakan untuk memprediksi suatu nilai dari variabel respon berdasarkan variabel prediktor. Adapun visualisasi antara $y$ aktual dengan $y$ prediksi dari model regresi nonparametrik spline truncated ditampilkan pada Gambar 4.

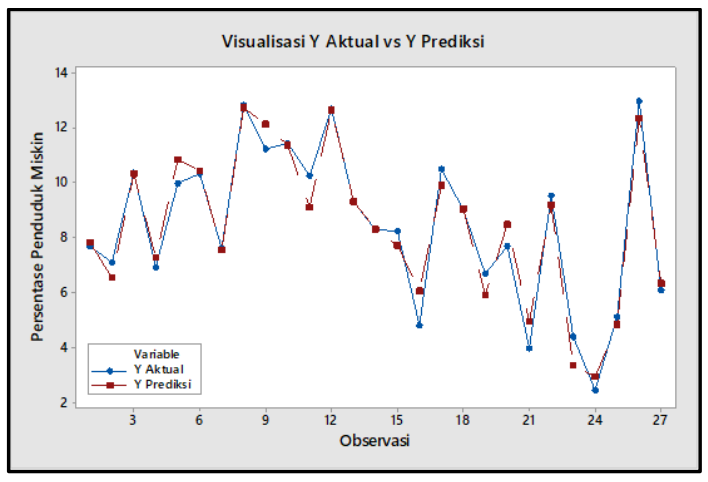

Gambar 4. Visualisasi $y$ aktual dengan $y$ prediksi

Berdasarkan gambar 4, diketahui bahwa hasil prediksi menggunakan model regresi nonparametrik dengan estimator Spline Truncated terlihat cenderung mengikuti pola data aktual, yang artinya model yang dibangun dapat dikatakan cukup baik untuk memprediksi persentase penduduk miskin Kabupaten/Kota di Provinsi Jawa Barat. Dengan didukung oleh nilai koefisien determinasi sebesar $95.33 \%$, yang artinya model regresi nonparametrik yang dibangun pada 
penelitian ini mampu menjelaskan pengaruh variabel prediktor terhadap variabel respon yaitu Persentase Penduduk Miskin sebesar 95.33\%.

Selanjutnya berdasarkan pengujian hipotesis baik simultan dan parsial, diketahui jika variabel prediktor yang digunakan pada penelitian ini berpengaruh secara signifikan terhadap variabel respon.

\section{KESIMPULAN DAN SARAN}

Berdasarkan hasil analisis dan pembahasan, maka dapat dituliskan kesimpulan sebagai berikut:

1. Pada pemodelan persentase penduduk miskin Kabupaten/Kota di Provinsi Jawa Barat Tahun 2020 menggunakan model regresi nonparametrik, diketahui bahwa model regresi regresi nonparametrik Spline Truncated yang terbaik adalah model dengan 3 titik knot. Hal ini ditunjukkan oleh nilai GCV yang paling minimum yaitu sebesar 2.14, dan nilai koefisien determinasi $\left(\mathrm{R}^{2}\right)$ sebesar $95.33 \%$.

2. Berdasarkan hasil pengujian hipotesis secara simultan, diperoleh nilai $F_{\text {hit }}$ sebesar 34.44 dimana nilai tersebut lebih besar daripada nilai $F_{(0.05,16,10)}$ sebesar 2.83 , sehingga diputuskan Tolak $H_{0}$, yang artinya variabel prediktor secara simultan mempengaruhi variabel respon.

3. Berdasarkan hasil pengujian hipotesis secara parsial, dapat disimpulkan bahwa semua variabel berpengaruh terhadap variabel respon yaitu persentase penduduk miskin Kabupaten/Kota di Provinsi Jawa Barat.

Saran yang dapat diusulkan untuk penelitian selanjutnya adalah dapat mengembangkan model estimator campuran untuk setiap variabel prediktor berdasarkan karakteristik pola hubungannya dengan variabel respon.

\section{DAFTAR PUSTAKA}

Budiantara, I. N. 2009. Spline Dalam Rgresi Nonparametrik dan Semiparametrik: Pidato Pengukuhan untuk Jabatan Guru Besar Institut Teknologi Sepuluh Nopember. Surabaya.

Bidari, D. R., dan Budiantara, I. N. 2020. Pemodelan Faktor yang Mempengaruhi Persentase Anak Putus Sekolah di Jawa Timur menggunakan Regresi Nonparamaterik Spline Truncated. Jurnal Sains dan Seni ITS, 9(2), 115-122

Budiantara, I. N. 2019. Regresi Nonparametrik Spline Truncated. ITS Press. Surabaya.

Draper, N. dan Smith, H. 1992. Applied Regression Analysis. John Wiley \& Sons, Inc. USA.

Andrea Tri Rian Dani ${ }^{1}$, Ludia Ni'matuzzahroh ${ }^{2} /$

J Statistika Vol. 14, No. 1, (2021)
Eubank, R. L. 1999. Nonparametric Regression and Spline Smoothing. Marcel Dekker. New York.

Dani, A. T. R., Adrianingsih, N. Y., dan Ainurrochmah, A. 2020. Pengujian Hipotesis Simultan Model Regresi Nonparametrik Spline Truncated dalam Pemodelan Kasus Ekonomi. JAMBURA Journal of Probability and Statistics, 1(2), 98-106.

Dani, A. T. R., Adrianingsih, N. Y., Ainurrochmah, A., dan Sriningsih, R. 2021. Flexibility of Nonparametric Regression Spline Truncated on Data without a Specific Pattern. Jurnal Litbang Edusaintech (JLE), 2(1), 37-43.

Dani, A. T. R., Ni'matuzzahroh, L., Ratnasari, V., dan Budiantara, I. N. 2021. Pemodelan Regresi Nonparametrik Spline Truncated pada Data Longitudinal. INFERENSI. 4(1), 47-55.

Dani, A. T. R. dan Adrianingsih, N. Y. 2021. Pemodelan Regresi Nonparametrik dengan Estimator Spline Truncated dan Deret Fourier. JAMBURA Journal of Mathematics, 3(1), 26-36.

Montgomery, D. C., Peck, E. A., dan Vining, G. G. 2012. Introduction to Linear Regression Analysis: Fifth Edition. John Wiley \& Sons, Inc. USA.

Montoya, E., Ulloa, N., dan Miller, V. 2014. A Simulation Study Comparing Knot Selection Methods with Equally Spaced Knots in a Penalized Regression Spline. International Journal of Statistics and Probability, 03(03), 96-110.

Rahim, F., Budiantara, I. N., dan Permatasari, E. O. 2019. Spline Truncated Nonparametric Regression Modeling for Maternal Mortality Rate in East Java, INFERENSI. 2 (1), 39-44.

Saputro, D. R. S., Demu, K. R., dan Widyaningsih, P. 2018. Nonparametric Truncated Spline Regression Model on Data of Human Development Index (HDI) in Indonesia. IOP Conf. Series: Journal of Physics, 1188.

Sholikha, M., Susilawati, M., dan Srinadi, I. G. A. M. 2019. Pemodelan Nilai Kurs terhadap Harga Saham pada Data Longitudinal Menggunakan Regresi Nonparametrik Spline Truncated. E-Jurnal Matematika, 8(4), 259263.

Yanthi, N. P. D., dan Budiantara, I. N. 2016. Pemodelan Faktor-Faktor yang Mempengaruhi Indeks Pembangunan Manusia menggunakan Regresi Nonparametrik Spline di Jawa Tengah. Jurnal Sains dan Seni ITS, 5(2), 157-162. 